\title{
Experimental and Performance Analyses with Frequently Discrete Usage of the Hot Storage Tanks
}

\author{
Ahmed Qandil', Khalid Al Rababa'a'2, Nader Aljabarin ${ }^{3 *}$, \\ Zaid Abu Al Ganem ${ }^{4}$, Rasheed Abdullah ${ }^{2}$ \\ 1 Mechanical and Industrial Engineering Department, Applied Science University Private, Amman, Jordan \\ 2 Mechanical Engineering Department, Tafila Technical University, Tafila, Jordan \\ 3 Natural Resources and Chemical Engineering Department, Tafila Technical University, Tafila, Jordan \\ ${ }^{4}$ Mechanical Engineering Department, AL Balqa Applied University, Amman, Jordan \\ * Corresponding author's e-mail: aljabarin@yahoo.com
}

\begin{abstract}
Hot water storage tanks are devices with high energy consumption, used widely in residential, industrial and commercial sectors. The hot storage tank is a key device in numerous applications such as electrical heaters, solar thermal storage, solar electrical energy production and many others. Its superior technology is favorable for the designers and has a great impact on the market competition. Hot water storage tanks were studied under continuous usage feature, for different inlet types, flow rates, thermal stratification in static and dynamic modes, both experimentally and numerically. The real discrete usage feature has not been analyzed in a proper way. In this study, the experimental and performance analyses with frequent discrete usage of the hot storage tank were performed. Different flow rates of 3, 6, and 9 1/min with 5, 10 and 20 min discrete usage waiting periods were studied. It was found that the thermocline thickness and mixing number increases for both increasing the flow rate due the increment in turbulent mixing potential and increasing the waiting period due to the increase in heat transfer time available between the hot and cold layers. The real data was drawn as is to permit further analyses and data comparison to other researchers. The effect of waiting periods can be used in solar HST to maximize the efficiency of solar collectors as the solar collector efficiency is high at low temperatures.
\end{abstract}

Keywords: storage tank, discrete usage, stratification, thermocline thickness, mix number, heat transfer, usable energy.

\section{INTRODUCTION}

The performance of hot fluid storage tanks is essential in energy saving and optimizing the available usable energy. Hot fluid storage tanks are important in the residential, commercial and industrial sectors, such as in domestic hot water cylinder, solar hot water storage cylinder, district heating systems and even in solar power generation. To all sectors, studying the performance of the hot fluid storage is highly appreciated. Many studies were conducted to understand the behavior of the hot fluid when mixed with cold fluid under different conditions and for different applications. Recently, an increased concern pertaining to the hot fluid storage tanks was observed, due to the increase in using hot storage tanks in new applications such as power generation.

Hot storage tank (HST) was the target for many researchers. Early in 1986 Oppel et al. modeled a single tank for stratified thermal storage using explicit finite difference method. The model was tested with the published experimental data and proved to be accurate. Zurigat et al. (1988) predicted the developed thermocline in a thermocline thermal storage tank. It was shown that predictions can be made by accounting for turbulent mixing at the inlet region by introducing an effective diffusivity factor. Davidson et al. (1994) developed a new index to quantify mix- 
ing in HST which is based on the height weighted energy; it was calculated from the vertical temperature profile. Later, the concern in HST was directed toward studying the fluid inlet to the tank and exit from the tank, their effects on the thermal stratification and possibility of saving energy. Jose Fernandez et al. (2007) studied experimentally the electric domestic hot storage tank, with different inlets and exits to improve the performance of the HST. The MIX index or mixing number were widely used in analyzing the HST; Gopalakrishnan and Srinivasa Murthy (2009) analyzed transient, two dimensional, mixed convection and thermal stratification in cylindrical HST, the mixing number was one of the parameters used to quantify the tank performance during charging mode. Moreover, García et al. (2013) compared two water inlet devices in a hot water storage tank during a thermal charge process: a sintered bronze conical diffuser (SBCD) and a conventional inlet elbow $(\mathrm{E})$. The temperatures were recorded by the thermocouples, the MIX number, as well as the thermocline, were used to quantify the performance of stratification. More quantifying parameters were then used for HST such as charging efficiency and the exergy concept, Petr Švarc (2014) investigated two different inlets into the storage tank the side and the downward inlets, the measured data during charging process were compared with the help of the thermocline thickness, $M I X$ number, equivalent lost height $(E L H)$ and efficiency based on the exergy concept. The used quantifying parameters seem to be sufficient to evaluate the HST performance, specially charging efficiency with the exergy of the system were considered. Due to the importance of HST in the recently new applications; increasing concern was given to HST, accelerated studies were conducted in the last few years. Njoku et al. (2014), performed an extensive survey on the performance methods based on energy, entropy and exergy analyses, he suggested entropy generation ratios, which are based on second law considerations, as effective in quantifying the performance of stratified thermal energy storage systems. The entropy generation number, Ns is suggested for future performance studies. Later research was directed toward experimental and numerical modeling of the HST combined with one of the applications such as solar hot water storage tank or HST power generation [Mevlut Arslan (2015) and Zilong Wang et al. (2017)]. The computational fluid dynamics (CFD) simulation program has got its role in simulating the behavior of HST as in Heming Yun et al. (2017) where the HST was simulated using differential internal structure to reduce the thermocline thickness and stratification. Ignacio Jos'e et al. (2017) simulated the HST for different inlet stratifying devices using CFD as a computational tool. The HST with phase change materials to improve the temperature difference between inlet and exit of the storage tank was performed [Porteiro et al. (2016) and Gürtürk et al. (2017)]. Alva et al. (2018) presented an overview of the HST usage in domestic, different power generation applications and thermal energy storage materials.

As observed from the previously mentioned literature, continuous charging and discharging of the HST were considered and analyzed, continuous charging or discharging feature does not accurately represent the real nature of using HST. The HST is discharged in a district manner according to the needs of the application. Researchers did not give the real case of discrete usage of the HST a valuable concern. In order to better understand what is happening within the HST, it is worth to study the realistic case of discrete usage nature of HST. In this study, experimental and thermal analysis of the real usage behavior of the HST was considered, frequent discrete usage of the HST was tested experimentally and the performance of the HST under different flow rates (3, 6 and $9 \mathrm{~L} / \mathrm{min})$ with different waiting periods $(5,10$, and $20 \mathrm{~min})$ were analyzed.

\section{EXPERIMENTAL SETUP}

In order to analyze the heat transfer in the HST, an experimental setup shown in Figure 1 was constructed. The setup consists of two constant temperatures supply tanks, the cold water source tank and the hot water source tank. The hot water source tank was heated using a gas heater for its fast heating and high energy value. These two tanks were connected to the main hot water storage tank by means of a water pump and control valves to control the circulation process i.e. filling the hot tank with the required temperature and recirculating until reaching a uniform temperature all over the tank, where hot water line was closed and cold water tank line was opened to perform the experiment.

The system was supplied by a flowmeter to measure and adjust the required flow rate $(3,6$, and $91 / \mathrm{min})$. The main test tank (HST) was equipped with fifteen K-Type thermocouples 


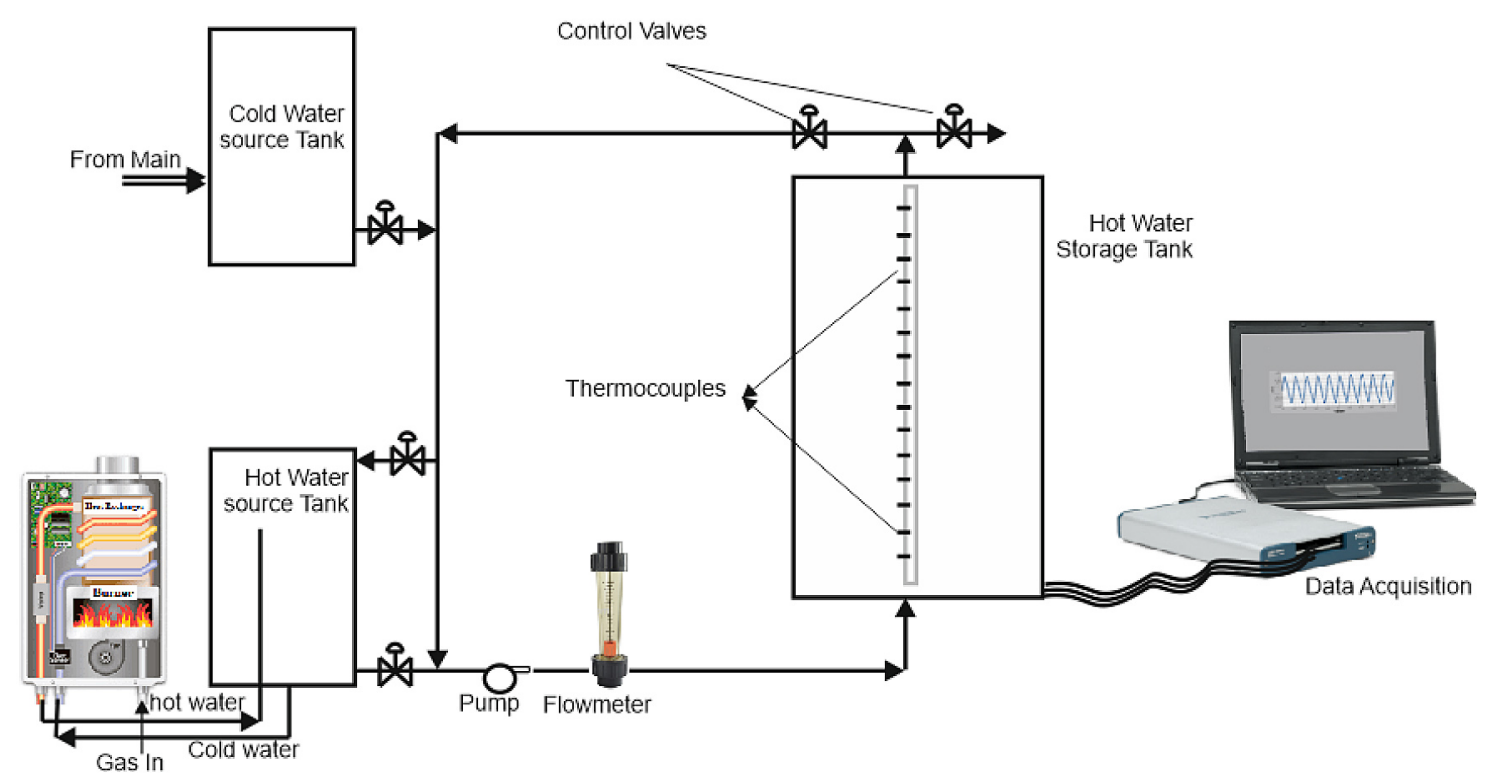

Figure 1. Schematic diagram of the experimental setup

set in a vertical line with $5 \mathrm{~cm}$ distance a part to sense the temperatures all over the HST, one extra thermocouple was used to measure the outside temperature of air. A data acquisition system was used to record the collected data from the sixteen thermocouples each 5 seconds and save these data in a proper file by the end of the experiment. The different control valves were used to control the direction of the flow and when maintenance is required. The experimental device (HST) design dimensions and experimental parameters were listed in Table 1.

The experiments was performed for different water usage flow rates, and different usage waiting periods as listed in the previous table.

Table 1. HST design dimensions and experiments parameters

\begin{tabular}{|l|c|}
\hline \multicolumn{2}{|c|}{ Hot water storage tank dimensions } \\
\hline Tank height & $78 \mathrm{~cm}$ \\
\hline Tank internal diameter & $42 \mathrm{~cm}$ \\
\hline Total number of thermocouples & 15 \\
\hline Distance between thermocouples & $5 \mathrm{~cm}$ \\
\hline Tank insulation thickness & $4 \mathrm{~cm}$ \\
\hline Tank total capacity & $108 \mathrm{~L}$ \\
\hline \multicolumn{2}{|c|}{ Experimental parameters } \\
\hline Cold water flow rates & 3,6, and $9 \mathrm{l} / \mathrm{min}$ \\
\hline Discrete usage timing & $5-10$ and 20 min \\
\hline Hot water initial temperature & $60{ }^{\circ} \mathrm{C}$ \\
\hline Features considered & Uncovered Supply \\
\hline
\end{tabular}

\section{EXPERIMENTAL RESULTS}

In order to analyze the effect of discrete flow on the stratification in the HST, experiments were performed for 3, 6 and $91 / \mathrm{min}$, and different periods of 5, 10 and $20 \mathrm{~min}$ waiting periods for in tank water initial temperature of $60^{\circ} \mathrm{C}$, cold water supply from the main. Figure 2 shows the real temperature distribution at different tank locations $(15,35,55$, and $75 \mathrm{~cm})$ from the base of the tank, with low flow rate $31 / \mathrm{min}$ and different waiting periods (5, 10 and $20 \mathrm{~min})$. It is clear from figure 2 that higher waiting periods reduce the supply temperature of the tank as a result of higher heat transfer time between the cold and hot water. This higher waiting period allows the cold water region to heat up, which may result in a higher supply temperature to the solar collector if used, which reduces the efficiency of the solar collector. This nature should be avoided whenever a solar system is used. Figure 3 shows the real temperature distribution at different tank locations $(15,35,55$, and $75 \mathrm{~cm})$ from the base of the tank, with high flow rate $91 / \mathrm{min}$ and different waiting periods (5, 10 and $15 \mathrm{~min})$. The temperature distribution for the high flow rate $91 / \mathrm{min}$ at different waiting periods shows a reduced effect on the supply temperature as the consumption of water is high. Even though the water supply temperature is high, the total amount of the supplied water seems to be reduced from Figure 3.

Figure 4 shows the temperature distributions of node $1(5 \mathrm{~cm}$ from the base at different waiting periods 5,10 and $20 \mathrm{~min}$, for $6 \mathrm{l} / \mathrm{min}$ water flow 

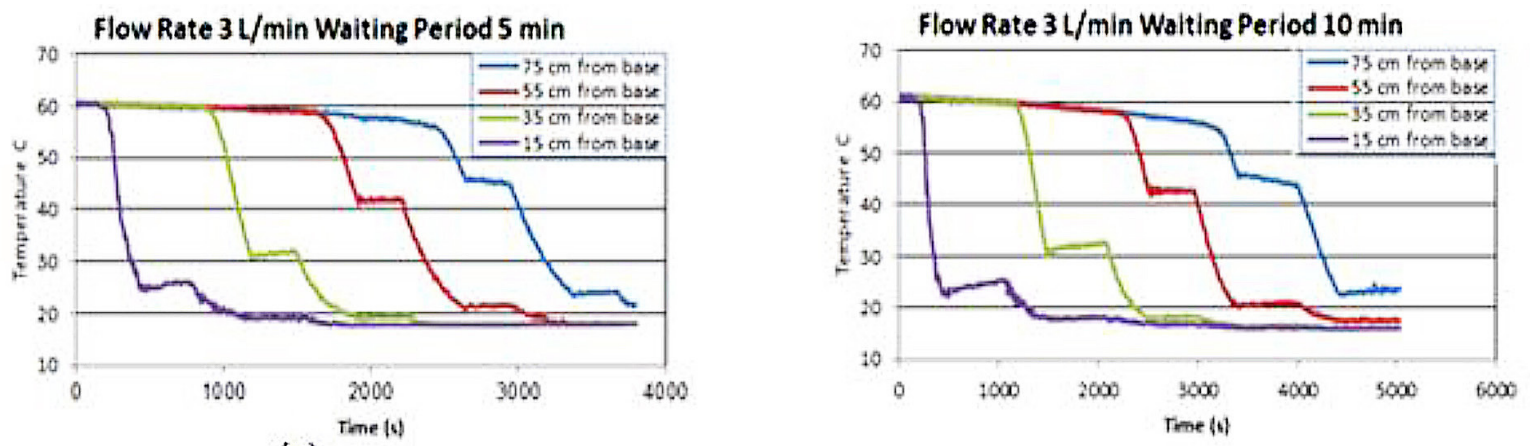

(a)

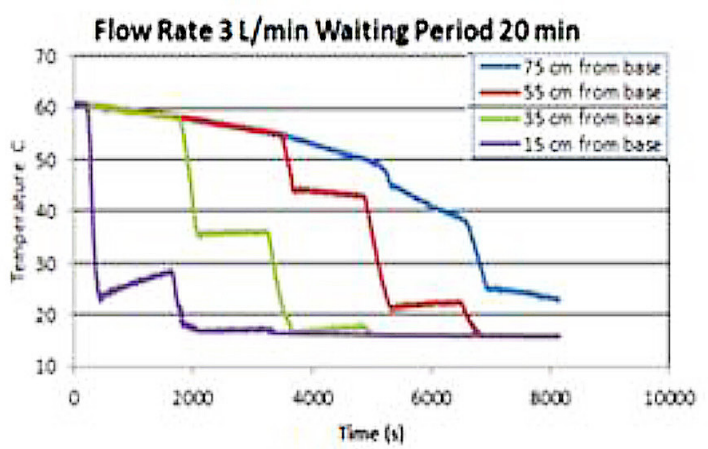

(b)

(c)

Figure 2. Temperature distribution at different tank locations, with flow rate $3 \mathrm{l} / \mathrm{min}$ and different waiting periods
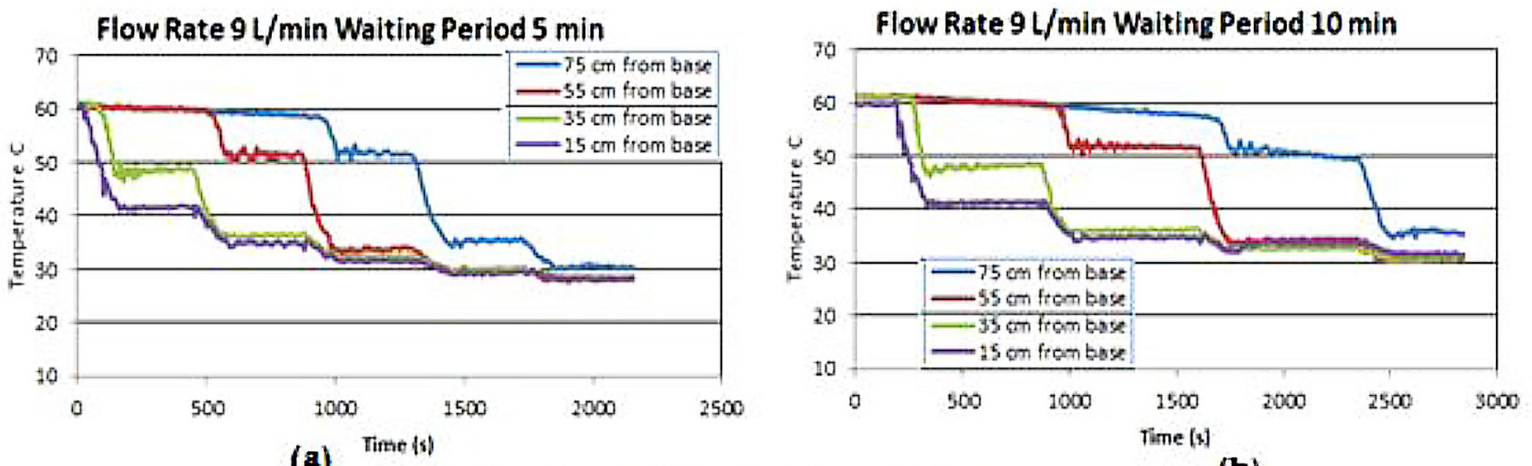

(a)

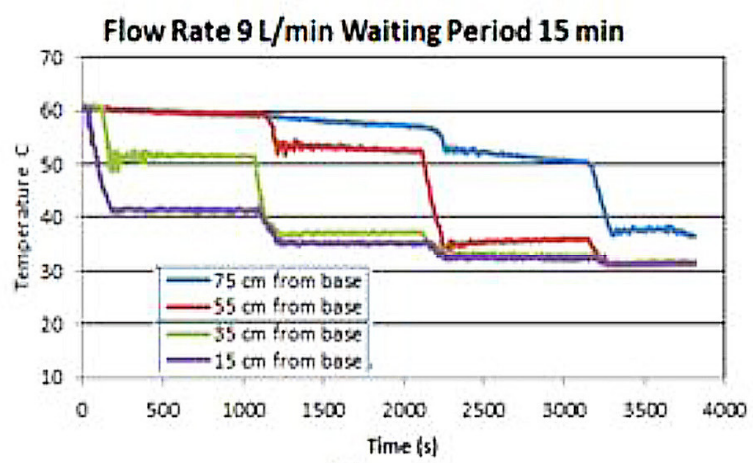

(b)

(c)

Figure 3. Temperature distribution at different tank locations, with flow rate $91 / \mathrm{min}$ and different waiting periods

rate. As it appears from figure $4 \mathrm{a}$ for the thermocouple at $5 \mathrm{~cm}$ from the base, the temperature of the thermocouple increases slightly as the waiting period increases, this due to the higher heat transfer time allowed between layers. Figure $4 \mathrm{a}$ shows three periods for the same thermocouple, the first waiting period shows a decrease in the thermocouple temperature as its temperature still much higher than the cold water supply temperature, whereas in the second waiting period, the 
temperature of the thermocouple increases, which means that the heat transfer from the upper nodes is more effective.

Figure $4 \mathrm{~b}$ shows the temperature distribution of node number 15 for the thermocouple at $75 \mathrm{~cm}$ from the base, the temperature of the thermocouple is not affected in the first waiting period of 5 min, but it is for the other two waiting periods. As it is observed $10 \mathrm{~min}$ and $20 \mathrm{~min}$ waiting periods affected the thermocouple at $75 \mathrm{~cm}$ away from the base by decreasing its temperature, this due the higher flow rate $(61 / \mathrm{min})$ and the longer waiting periods (10 $\mathrm{min}$ and $20 \mathrm{~min}$ ).

\section{PERFORMANCE ANALYSES}

In this study, the thermocline thickness and mixing number will be chosen to quantify the performance of the HST; the other quantifying parameters will lead to the same conclusions. The data was given in the figures and other parameters can be calculated.

\section{Thermocline thickness}

The water temperature variation in the stratified HST for discrete supply mode consists of different regions; hot water at the top, cold water at the bottom and stepped thermocline region in the middle. The position of the thermocline region is defined by the boundary lines of cold water and hot water in the tank. The effect of cold water supply flow rate and waiting period is to be analyzed in this section. Figure 5a shows the variation of thermocouples temperature with time (inside the HST with 5 min time interval for $31 /$ min flow rate). Figure $5 \mathrm{~b}$ shows the variation of thermocouples temperature with time (inside the HST with 20 min time interval for $3 \mathrm{l} / \mathrm{min}$ flow rate). It is clear from both figures that the thermocline thickness grows with time, as mixing more water and heat transfer time increases. It is also notified that for time $1900 \mathrm{sec}$ and 2200 sec both temperature distributions are identical, this is due the waiting period intersection. When the time interval was increased, the thermocline thickness decreases with time, especially for long waiting periods the internal heat transfer become more effective.

In order to visualize this effect more clearly, the influence of waiting period on the nodes temperatures is to be analyzed for a fixed time
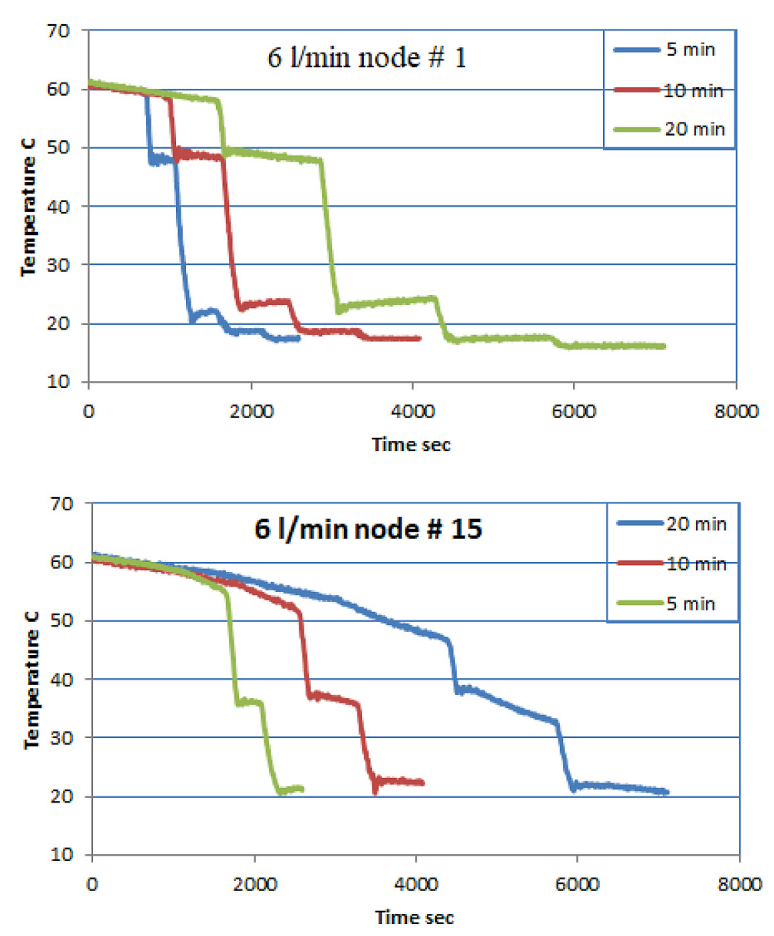

Figure 4. The temperature distributions of (a) node 1 and (b) node $15(15 \mathrm{~cm}$ and $75 \mathrm{~cm})$ from the base at different waiting periods 5,10 and $20 \mathrm{~min}$, for $6 \mathrm{l} / \mathrm{min}$ water flow rate

$1600 \mathrm{sec}$, as this line is intermediate between the temperature distributions. Figure 6 shows the thermocouples temperature distribution at a fixed time for both different flow rates and different waiting periods. Here, the thermocline thickness is obvious and it decreased along with the waiting period, as expected above.

In Figure 7, the thermocline thickness was calculated for $31 / \mathrm{min}$ flow rate $5 \mathrm{~min}$ waiting period. The thermocline thickness increased steadily along with time due to mixing between the hot water and cold water. The effect of waiting period affects the thermocline thickness as heat was transferred between the layers.

\section{Mixing Number}

Mixing number was used to measure the mixing effect in hot water storage tanks; it was given by the equation, N. Gopalakrishnan (2009),

$$
M I X=\frac{M_{\text {ideal }}-M_{\text {actual }}}{M_{\text {ideal }}-M_{\text {fully mixed }}}
$$

where:

$$
M=\sum_{i=1}^{i=n} \rho_{i} V_{i} c_{p} T_{i} Y_{i}
$$




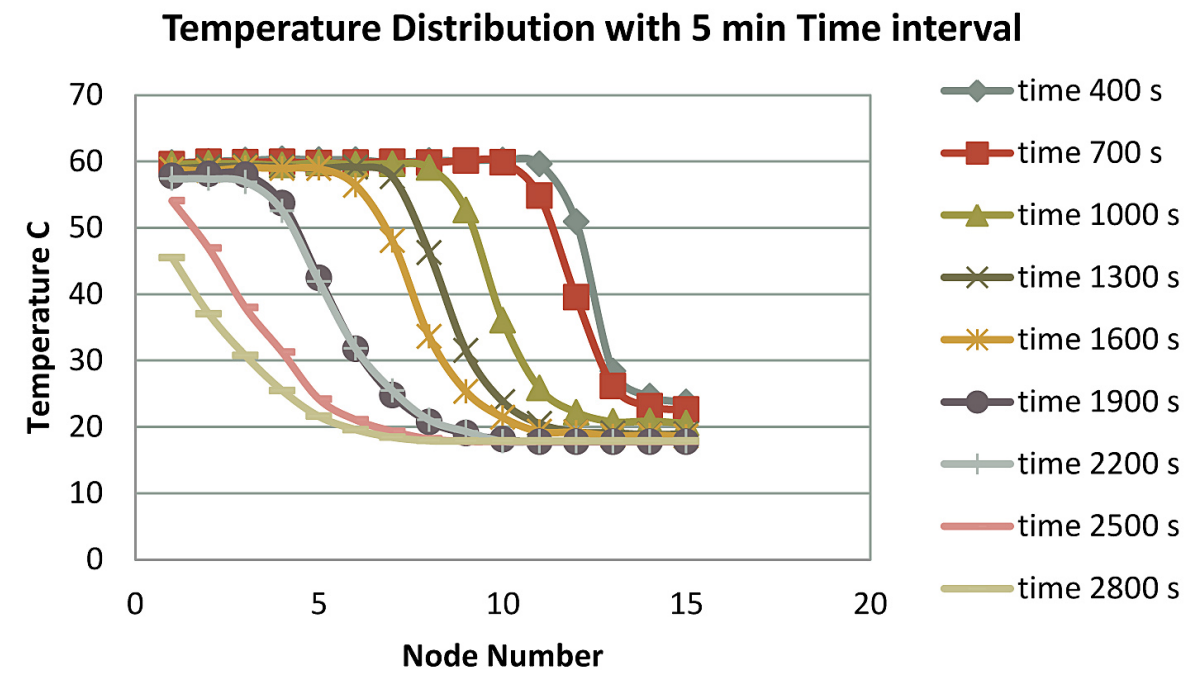

Temperature Distribution with $\mathbf{2 0}$ min Time interval

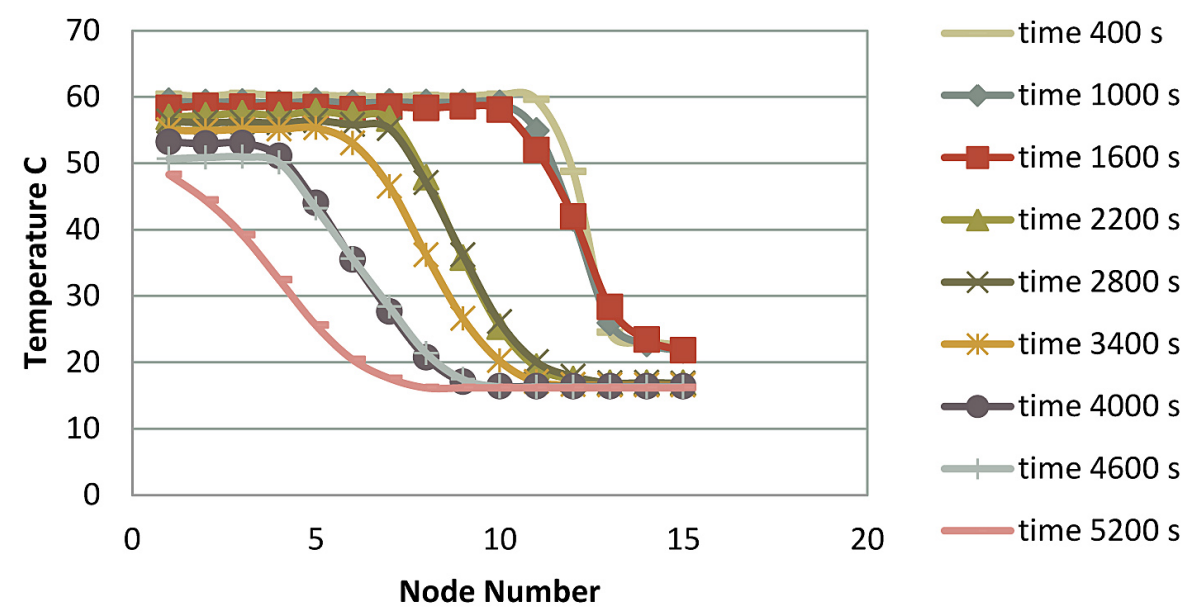

Figure 5. The variation of temperature of thermocouples inside the HST (a) with 5 min time interval, (b) with 20 min time interval and $31 /$ min flow rate

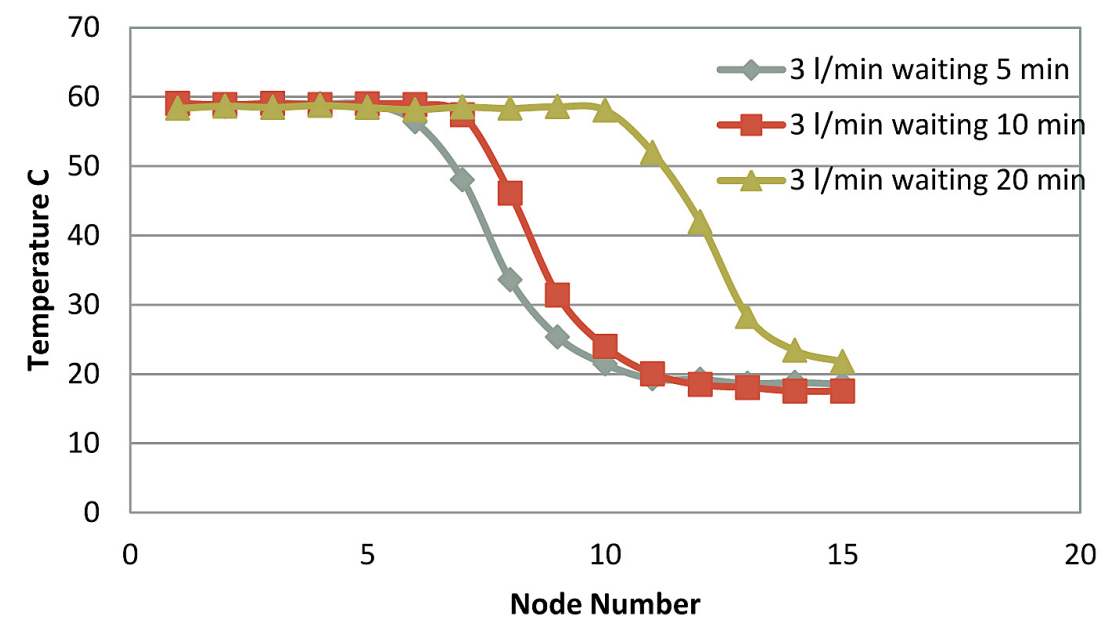

Figure 6. The effect of waiting period for the same flow rate $31 / \mathrm{min}$ for time $1600 \mathrm{sec}$ 


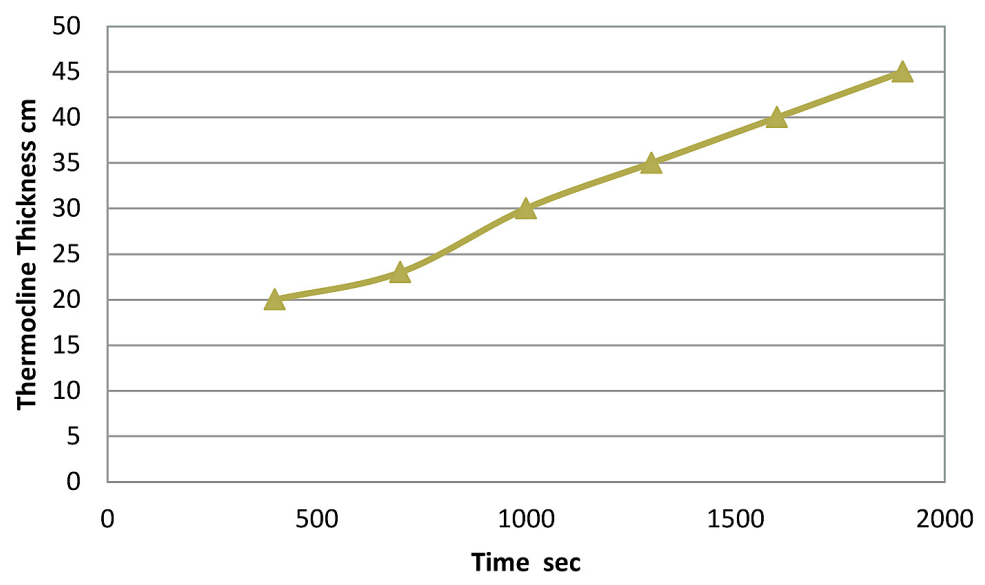

Figure 7. The thermocline thickness for flow rate $31 / \mathrm{min}$ and $5 \mathrm{~min}$ waiting period

$\rho_{i}$ is the fluid density,

$V_{i}$ fluid sub-volume,

$T_{i}$ sub-volume temperature,

$Y_{i}$ distance to the node and $\mathrm{n}$ is the number of nodes.

The mixing number (Figure 8) at the beginning is almost equal to one as $M_{\text {ideal }}=M_{\text {actual }}=M_{\text {fully mixed }}$ ' as cold water enters the hot tank $M_{\text {fully mixed }}$ the denominator increases reducing the value of the mixing number, as soon as the first node starts feeling the cold water temperature the effect of mixing becomes clear and the nominator difference start approaching the denominator difference reaching the value one again.

In order to clarify the effect of different waiting periods and flow rate on the mixing number with time. Figure 9 was drawn for $31 / \mathrm{min}$ with 5 and 20 min waiting periods and $91 / \mathrm{min}$ with 5 min waiting period.

In order to judge on the performance of the MIX number with time, a dimensionless time parameter was defined as:

$$
\tau=\frac{t}{t}
$$

where $\tau$ is the dimensionless time, $\mathrm{t}$ time is seconds and $t^{\prime}$ is the total time consumed in the experiment.

Whenever there is a temperature variation in the experimental inlet or exit temperatures; a dimensionless temperature can be defined to eliminate these differences as,

$$
\theta=\frac{T-T_{\infty}}{T_{\max }-T_{\infty}}
$$

where: $\phi$ is the dimensionless temperature,

$T_{\infty}$ is the ambient temperature,

$T_{\max }^{\infty}$ is the maximum water temperature,

$T$ is the water instantaneous temperature.

From figure 10 and after using dimensionless time, it can be stated that raising the mass flow rate increases the mixing number for a fixed waiting period due to higher turbulent mixing potential in the flow, whereas the increment in the wait-

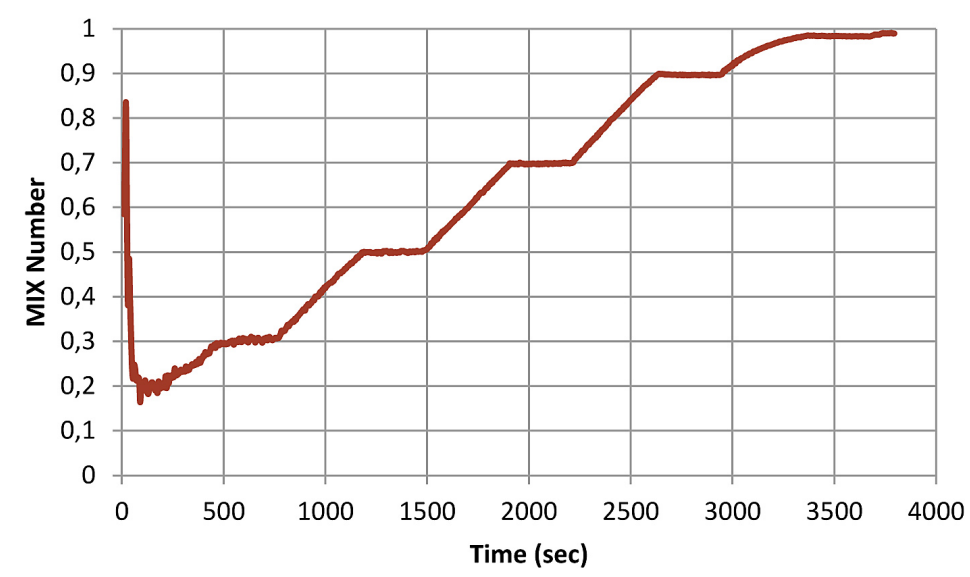

Figure 8. The variation of mixing number with time for $31 / \mathrm{min}$ and $5 \mathrm{~min}$ waiting period 


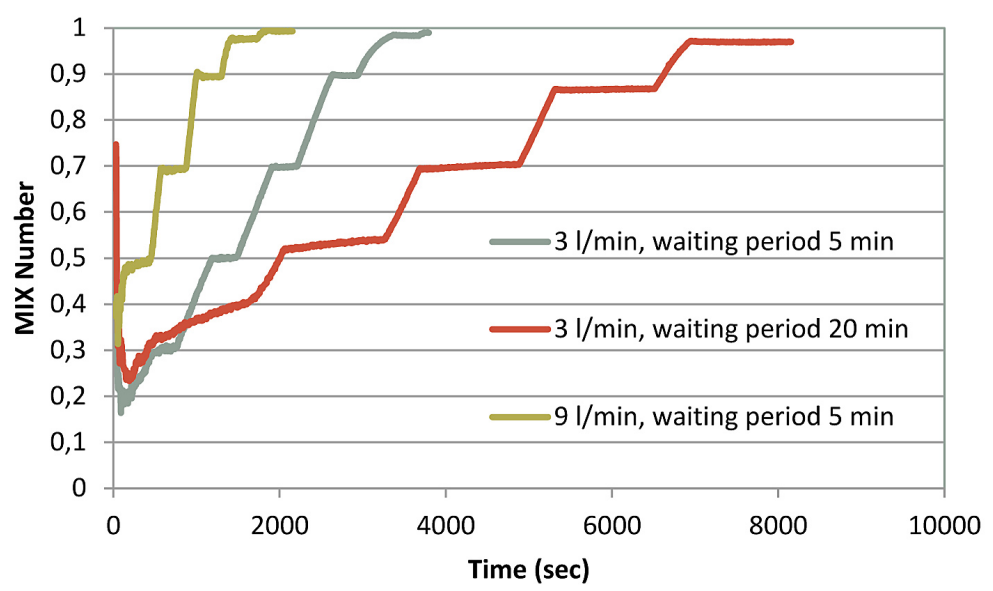

Figure 9. The effect of different waiting periods and flow rate on the mixing number with time

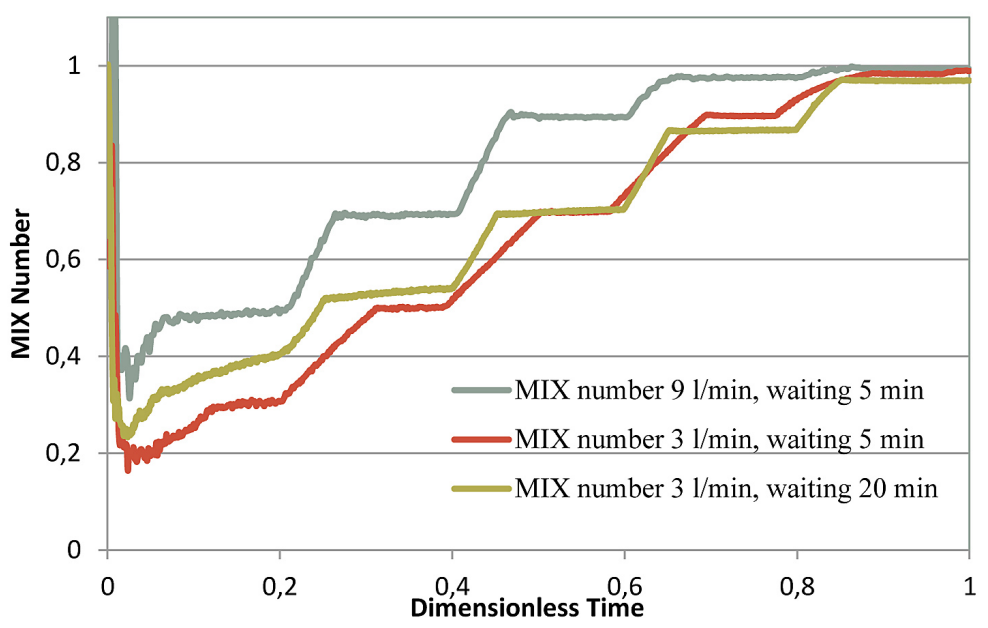

Figure 10. The effect of different waiting periods and flow rate on the mixing number with dimensionless time

ing period in increases the mixing number due to the higher heat transfer period between layers.

\section{CONCLUSION}

The hot fluid storage tanks are valuable devices in many applications. Increasing the ability of these devices in saving energy, supplying its maximum stored energy and getting benefit of its temperature distribution will make these devices more attractive, more competitive and may create new applications in industry for such efficient devices. Studying the continuous charging or discharging gives a good idea on the behavior of HST but it does not represent the real usage. The discrete supply feature is the real usage feature of HST. In this study the HST behavior for different flow rates $(3,6$ and $91 / \mathrm{min})$ and different waiting periods $(5,10$ and $20 \mathrm{~min})$ were studied experimentally, listed and analyzed using the mixing number and the thermocline thickness. It was found that the thermocline thickness and mixing number increased for both increasing the flow rate due the increment in turbulent mixing potential and increasing the waiting period due to the raise in heat transfer time available between the hot and cold layers. The real data was drawn as is to permit other researchers to conduct further analyses and compare data. The effect of waiting periods can be used in solar HST to maximize the efficiency of solar collectors as the solar collector efficiency is high at low temperatures.

\section{REFERENCES}

1. Alva G, Lin Y, Fang G. 2018. An overview of thermal energy storage systems. Energy, doi: 10.1016/j. energy.2017.12.037.

2. Arslan M., Igci A.A. 2015. Thermal performance of a vertical solar hot water storage tank with a 
mantle heat exchanger depending on the discharging operation parameters. Solar Energy 116, 184 204, .doi: 10.1016/j.solener.2015.03.045.

3. Davidson J. H., Adams D. A., Miller J. A. 1994. A Coefficient to Characterize Mixing in Solar Water Storage Tanks. Transactions of the ASME, Vol. 116, May.

4. Fernandez-Seara J., Uhia F.J., Sieres J. 2007. Experimental analysis of a domestic electric hot water storage tank. Part II: dynamic mode of operation. Applied Thermal Engineering 27, 137-144.

5. García Mari E., Gasque Albalate M., Gutiérrez Colomer R.P., Ibáñez Solís F., González Altozano P. 2013. A new inlet device that enhances thermal stratification during charging in a hot water storage tank." Applied Thermal Engineering. 61(2): 663-669, doi: 10.1016/j.applthermaleng.2013.08.023.

6. Gopalakrishnan N., Srinivasa Murthy S. 2009. Mixed Convective Flow and Thermal Stratification in Hot Water Storage Tanks during Discharging Mode. Applied Solar Energy, 45(4), 254-261.

7. Gürtürk M., Koca A., Öztop H.F., Varol Y. \& Şekerci M. 2017. Energy and exergy analysis of a heat storage tank with novel eutectic phase change material layer of a solar heater system. International Journal of Green Energy, doi: 10.1080/15435075.2017.1358625.

8. Heming Yuna, Fangfang M.A., Xunhu Guo, Baoming Chen 2017. Field Synergy Analysis of Thermal Storage Effect of Solar Energy Storage Tank. Procedia Engineering 205, 4001-4008, doi: 10.1016/j. proeng.2017.09.866.

9. Moncho-Esteve I.J., Gasque M., Gonz'alezAltozano P., Palau-Salvador G., 2016. Simple inlet devices and their influence on thermal stratification in a hot water storage tank. Energy and Buildings, doi: 10.1016/j.enbuild.2017.06.012.

10. Njoku H.O., Ekechukwu O.V., Onyegegbu S.O. 2014. Analysis of stratified thermal storage systems: An overview. Heat Mass Transfer, 50, 10171030. DOI: 10.1007/s00231-014-1302-8.

11. Oppel F.J., Ghajar A.J. and Moretti P.M. 1986. Computer Simulation of Stratified Heat Storage. Applied Energy, 23, 205-224.

12. Penkova N., Harryzanov N. 2014. Analysis and optimization of temperature stratification in a thermal energy storage tank. Energy and Sustainability V, WIT Transactions on Ecology and The Environment, 186, 469-478, doi: 10.2495/ ESUS140401.

13. Porteiro J., Míguez J.L., Crespo B., de Lara J., Pousada J.M. 2016. On the Behavior of Different PCMs in a Hot Water Storage Tank against Thermal Demands. Materials 9, 213, doi: 10.3390/ ma9030213.

14. Švarc P., Seidl J., Dvorák V. 2014. Experimental study of influence of inlet geometry on thermal stratification in thermal energy storage during charging process. EPJ Web of Conferences, 67, 02114, doi: 10.1051/epjconf/20146702114.

15.Zilong Wang, Hua Zhang, Binlin Dou, Huajie Huang, Weidong Wu, Zhiyun Wang 2017. Experimental and numerical research of thermal stratification with a novel inlet in a dynamic hot water storage tank. Renewable Energy, doi: 10.1016/j. renene.2017.04.007.

16. Zurigat Y.H., Ghajar A.J. \& Moretti E.M. 1988. Stratified Thermal Storage Tank Inlet Mixing Characterization. Applied Energy, 30, 99-111. 